УдК 334.012 .6

\title{
ТЕНДЕНЦИИ РАЗВИТИЯ МАЛОГО И СРЕДНЕГО БИЗНЕСА В БЕЛАРУСИ
}

\author{
О.В. ТЕЛЕГИНА \\ Гомельский государственный технический университет имени П.О. Сухого, \\ г. Гомель
}

\begin{abstract}
Аннотация
В статье приведены критерии отнесения предприятий к малому и среднему бизнесу. Оиенена роль бизнеса в основных экономических показателях. Рассмотрена структура производства малого и среднего бизнеса по отраслям экономики, определен их вклад в отрасли промышленности. Дана оценка институциональной среды ведения бизнеса в Беларуси. Обозначены основные факторы, сдерживаюшие рост бизнеса.
\end{abstract}

Annotation

The article presents the criteria for classifying enterprises to small and medium businesses. The role of business in the main economic indicators. The structure of the production of small and medium businesses by industry sector, to determine their contribution to the industry. The evaluation of the institutional environment of doing business in Belarus. Identified the main factors constraining business growth.

\section{ВВЕДЕНИЕ}

Становление и развитие сектора малого и среднего бизнеса в странах с переходной экономикой позволяет решить проблему роста безработицы, связанную с высвобождением излишней рабочей силы с крупных государственных предприятий, и формирования среднего класса, способного обеспечить устойчивый покупательский спрос. Способность развиваться для бизнеса определяется сформированной в экономике институциональной средой и текущей рыночной коньюнктурой. Детальная оценка состояния и динамики развития малого и среднего предпринимательства необходима для разработки адекватных реальной ситуации мер экономической политики в области поддержки малого бизнеса. Анализ его состояния проводится на основе обзора статистических данных, результатов опроса предпринимателей, оценки законодательной базы. Ежегодные опросы по проблемам развития малого бизнеса и оценке его потенциала проводятся Исследовательским центром ИПМ, Международной финансовой корпорацией в рамках международного проекта Doing Business. Аналитические обзоры представлены сотрудниками Белорусского экономического исследовательского центра BEROC (М. Акулова, 2015), Исследовательского центра ИПМ (Д. Урютина, И. Михайлова, 2015, А. Скриба, 2015).

\section{РЕЗУЛЬТАТЫ И ИХ ОБСУЖДЕНИЕ}

Критерии отнесения предприятий к субъектам малого бизнеса разрабатываются на законодательном уровне, так как это является необходимым для четкого определения малых предприятий при оказании государственной поддержки, а также для применения налогообложения малого бизнеса. В качестве критериев в мировой практике чаще применяются численность занятых, объем продаж (оборот), стоимость активов. Кроме того, возможна дифференциация критериев в отраслевом разрезе. Белорусская статистика до 2008 года в соответствии с законом «О государственной поддержке малого предпринимательства в Республике Беларусь» от 16.10 .1996 г. считала субъектов малого предпринимательства по критерию численности занятых в отраслевом разрезе. Так, в промышленности предприятие считалось малым с численностью занятых до 100 человек, сельском хозяйстве и научно-технической сфере - до 60 человек, строительстве и оптовой торговле - до 50 человек, розничной торговле и бытовом обслуживании - до 30 человек, других отраслях - до 25 человек. С 2009 года в соответствии с законом «О поддержке малого и среднего предпринимательства» от 01.07.2010 г., во-первых, стали выделять субъектов среднего бизнеса, во-вторых, отказались от отраслевой дифференциации критерия численность занятых. В настоящее время статистика к субъектам малого и среднего бизнеса в Беларуси относит индивидуальных предпринимателей, микроорганизации с численностью занятых до 15 человек, малые организации с численностью от 16 до 100 человек, средние организации с численностью от 101 до 250 человек.

Однако получить объективные межстрановые сопоставления данная классификация не позволяет, так как не учитывает оборот предприятия, вследствие чего крупные по обороту фирмы могут быть отнесены к малому и среднему бизнесу только по критерию среднесписочной численности занятых, что ведет к завышению экономических показателей. 


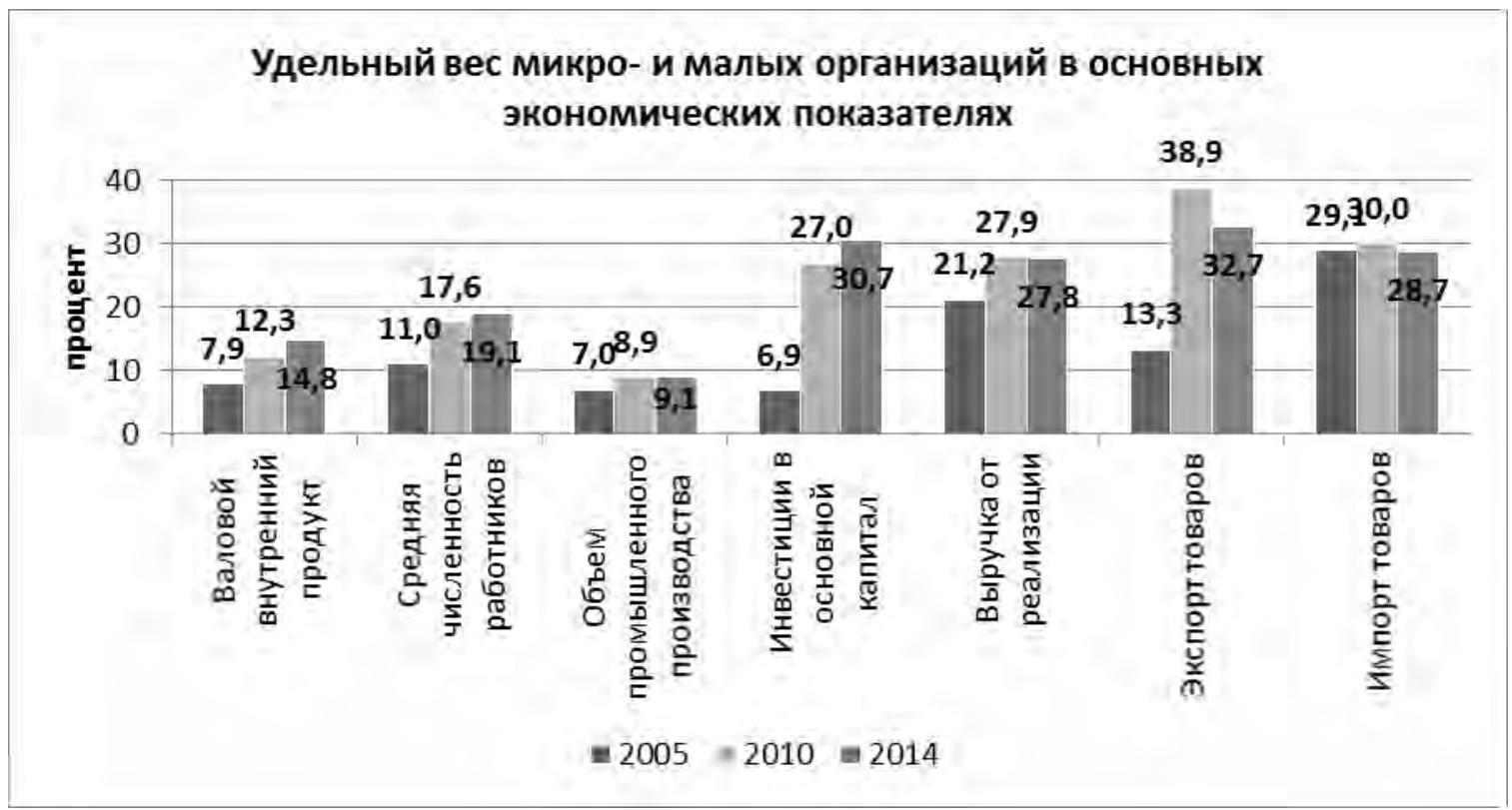

Рисунок 1. Удельный вес субъектов малого бизнеса в основных экономических показателях [по данным Белстат]

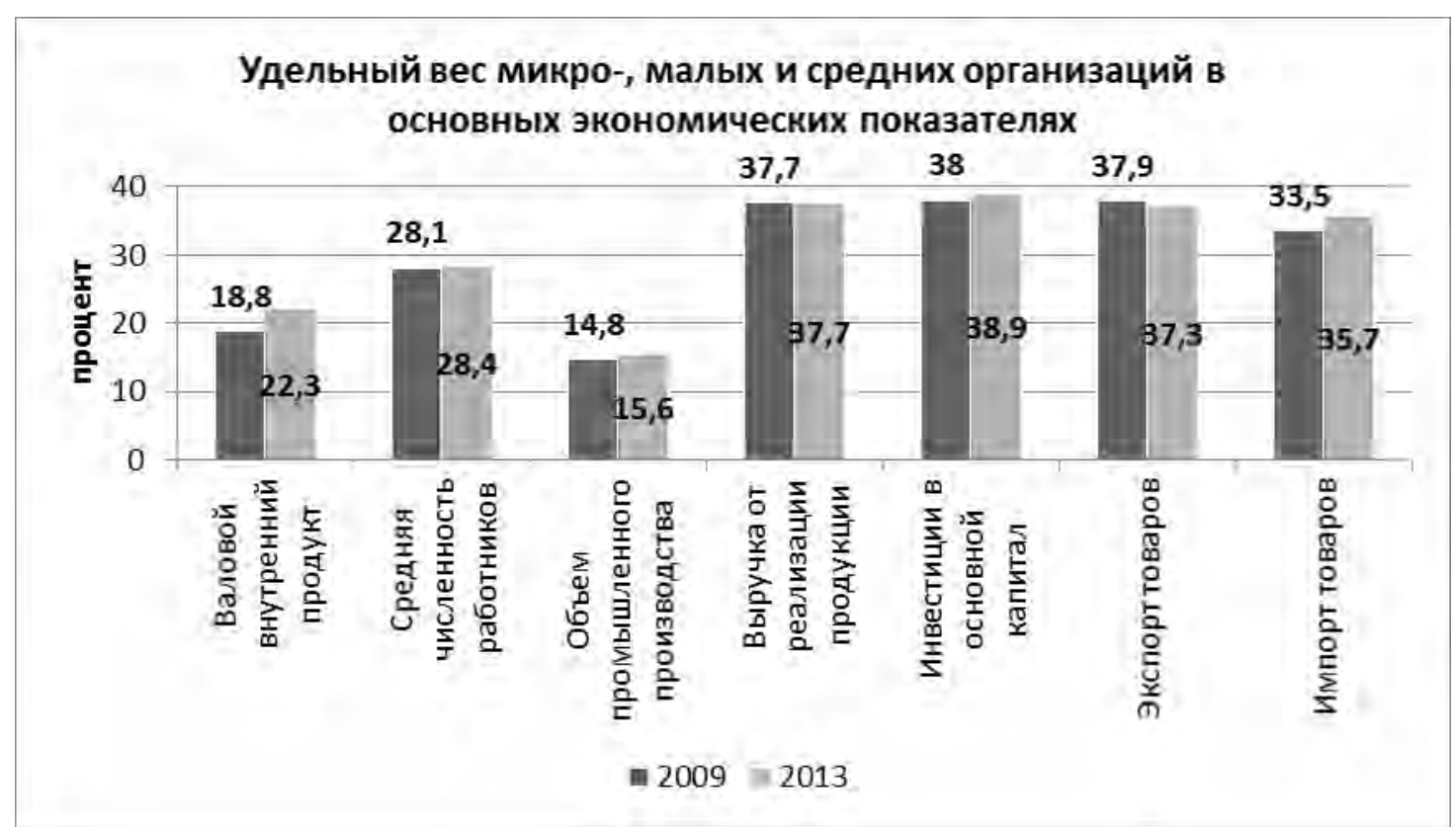

Рисунок 2. Удельный вес субъектов малого и среднего бизнеса в основных экономических показателях (по данным[1])

Рассмотрим роль и тенденции развития малого и среднего бизнеса в экономике Республики Беларусь. Оценим вклад малого и среднего бизнеса" в основные экономические показатели. Доля малого бизнеса в создании валового внутреннего продукта (ВВП) составила 14,8\% по итогам 2014 г. (рис.1). С 2005 г. (7,9\%) рост его доли в ВВП составил около 7\%, т.е. ежегодный прирост удельного веса в ВВП - менее одного процента. Учитывая, что в 2005 году статистика относила к субъектам малого предпринимательства предприятия с численностью занятых до 100 человек только в промышленности, то темпы роста доли данного сектора в ВВП за последние 9 лет выглядят еще скромнее. Субъекты малого и среднего предпринимательства вместе создали 22,3\% ВВП в 2013 году (рис. 2), что является относительно невысоким показателем по сравнению с развитыми странами, где доля данного сектора составляет более $50 \%$.

Социальная роль малого бизнеса проявляется в создании рабочих мест (особенно в период массовой безработицы), что подтверждается более высокой долей его в занятости населения по сравнению с долей в ВВП: 19,1\% занято в малом бизнесе от общей численности занятых в экономике в 2014 году (рис.1) и 28,4\% - в малом и среднем бизнесе в 2013 году (рис.2). Незначительное изменение доли занятых в секторе малого и среднего предпринимательства за 4 года (в 2009 году - 28,1\%) при более высоких темпах роста его доли в создании ВВП может означать рост производительности труда в данном секторе.

Доля в выручке от реализации и в инвестициях в основной капитал превышает их долю в ВВП и может свидетельствовать о бо́льшей доходности и инвестиционной активности по сравнению с крупными предприятиями. Однако

\footnotetext{
* Далее анализ представлен только по микро-, малым и средним организациям. Индивидуальные предприниматели в силу ограниченности статистических данных в обзор не включены, что вызывает искажения в оценке показателей.
} 
отсутствие положительной динамики в обоих показателях за четыре исследуемых года при некотором увеличении их доли в ВВП может указывать на наличие финансовых ограничений в этом периоде, возможно, связанных с белорусским валютным кризисом 2011 года.

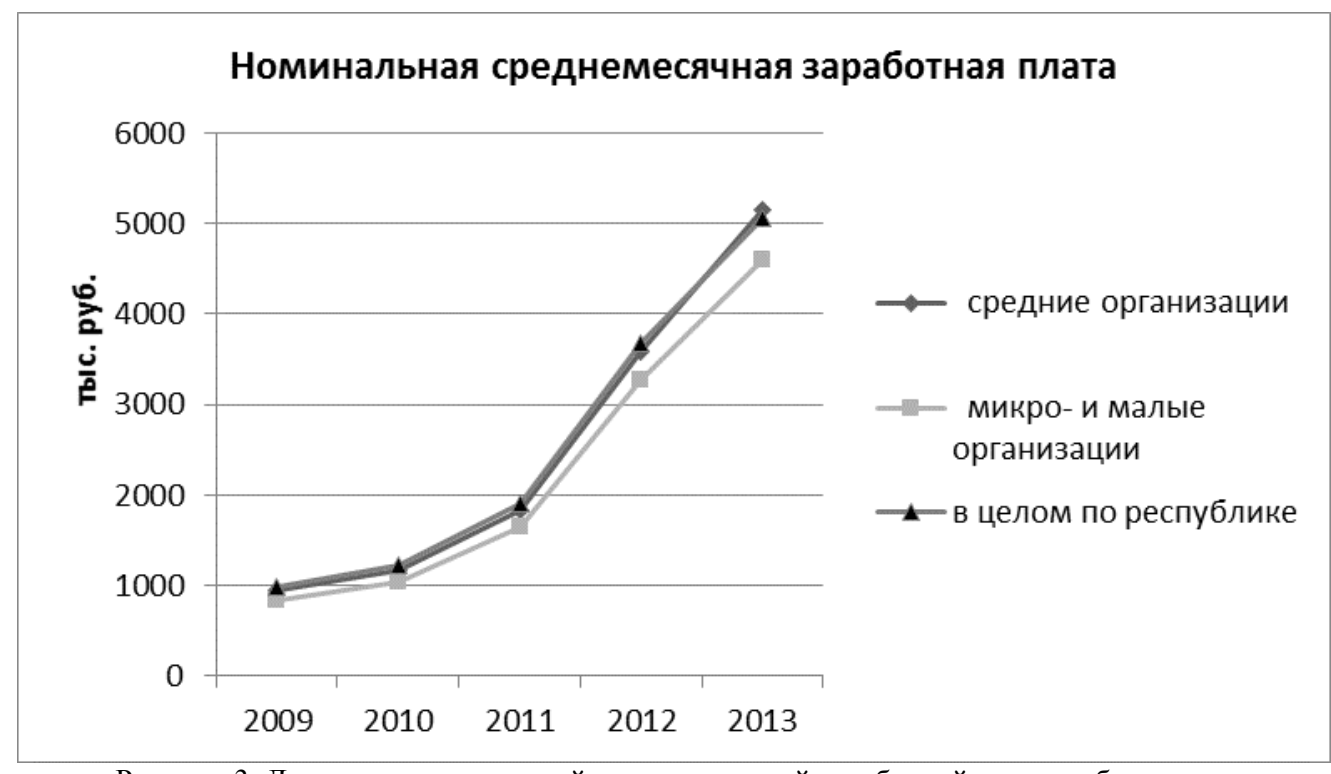

Рисунок 3. Динамика номинальной среднемесячной заработной платы субъектов малого и среднего бизнеса (по данным [1], [2])

Уровень номинальной заработной платы у средних организаций совпадает с уровнем средней номинальной заработной платы по республике в целом (рис. 3), а у микро- и малых организаций незначительно отстает от среднего республиканского уровня.

Относительным финансовым показателем деятельности предприятия является рентабельность продаж, которая показывает удельный вес прибыли в составе выручки от реализации продукции. Сравнение рентабельности продаж субъектов малого и среднего бизнеса с республиканским значением показывает незначительное его отставание за период с 2009 по 2012 годы и выравнивание в 2013 году на уровне 6,6\% (рис. 4). Всплеск уровня рентабельности в 2011 году связан со скачком инфляции в этом периоде и соответственно ростом номинальных показателей.

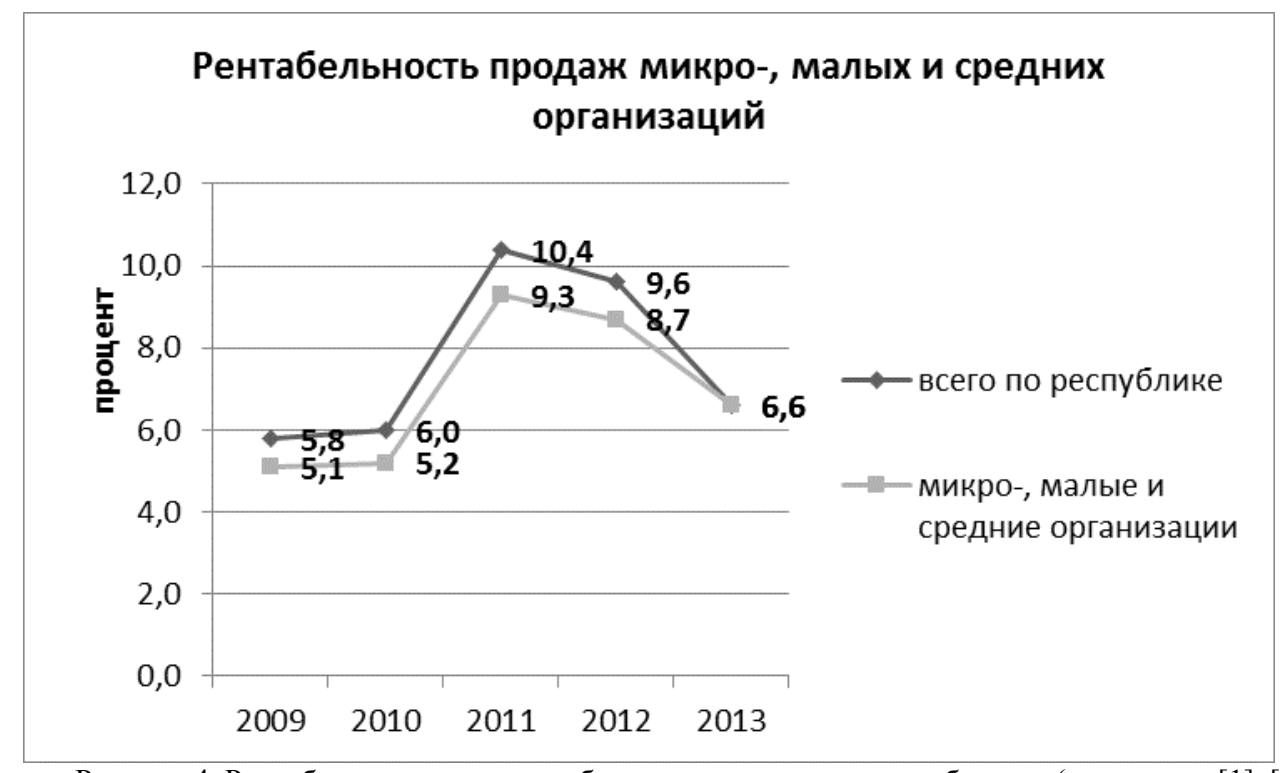

Рисунок 4. Рентабельность продаж субъектов малого и среднего бизнеса (по данным [1], [2])

Рассмотрим структуру производимой малым и средним предпринимательством продукции с точки зрения секторного подхода: деления ее на производящую сферу и сферу услуг. В отраслевой структуре всей производимой субъектами малого и среднего бизнеса продукции сфера производства составила 57,0\% в 2013 г., сфера услуг - 42,9\% (рис. 5). Однако преобладание сферы производства над сферой услуг достигнуто за счет вклада средних организаций, в структуре производимой продукции которых 73,4\% - это отрасли из сферы производства, а 26,6\% - сфера услуг. Бо́льшая доля производимой микро- и малыми организациями продукции создается в сфере услуг (51,8\% в 2013г.), которая не требует значительных капиталовложений. Но изменения, произошедшие в структуре производства субъектов малого предпринимательства с 2009 по 2013 гг,, демонстрируют тенденцию увеличения доли сферы производства 
и снижения доли сферы услуг (рис.6). В целом значительных изменений в структуре производимой продукции организациями малого и среднего бизнеса с позиций секторного подхода за период с 2009 по 2013 гг. не произошло.

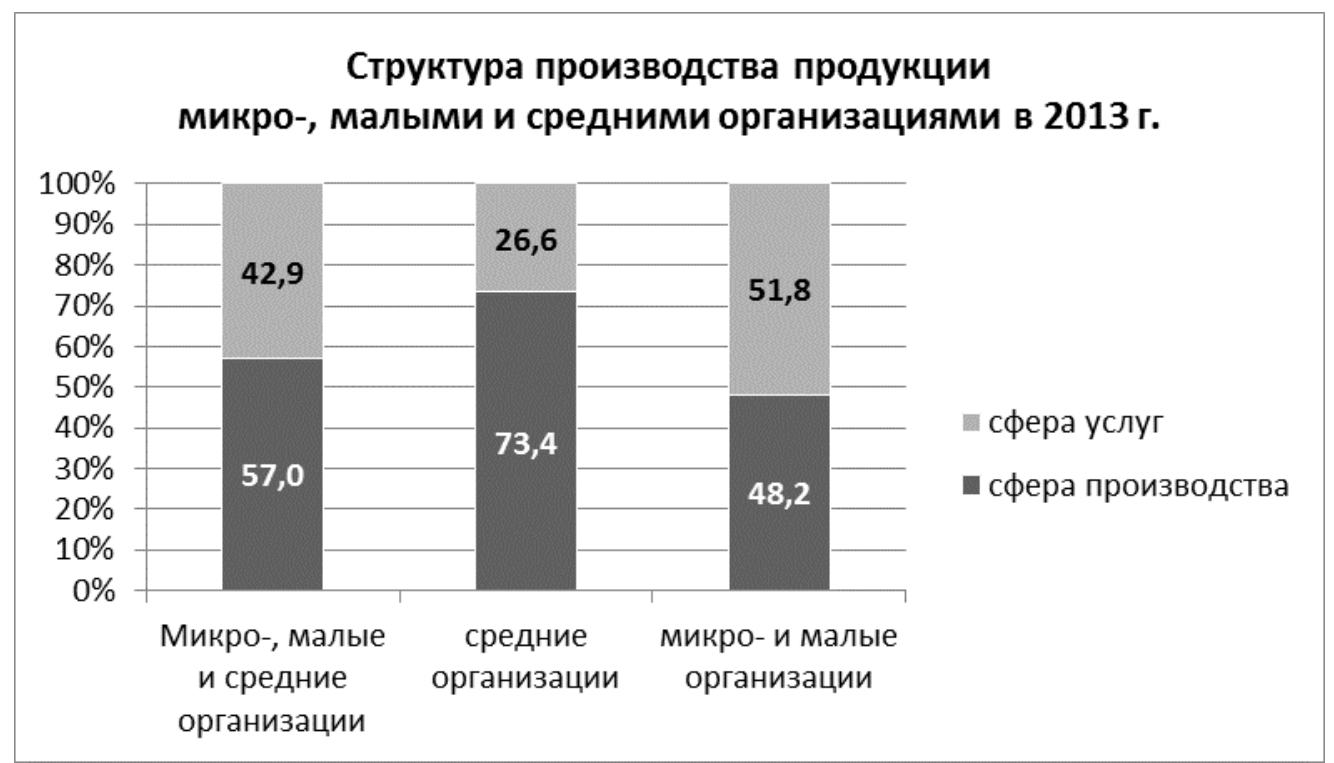

Рисунок 5. Структура производства продукции (работ, услуг) субъектами малого и среднего бизнеса по видам экономической деятельности в 2013 г. (расчеты автора по данным [1])

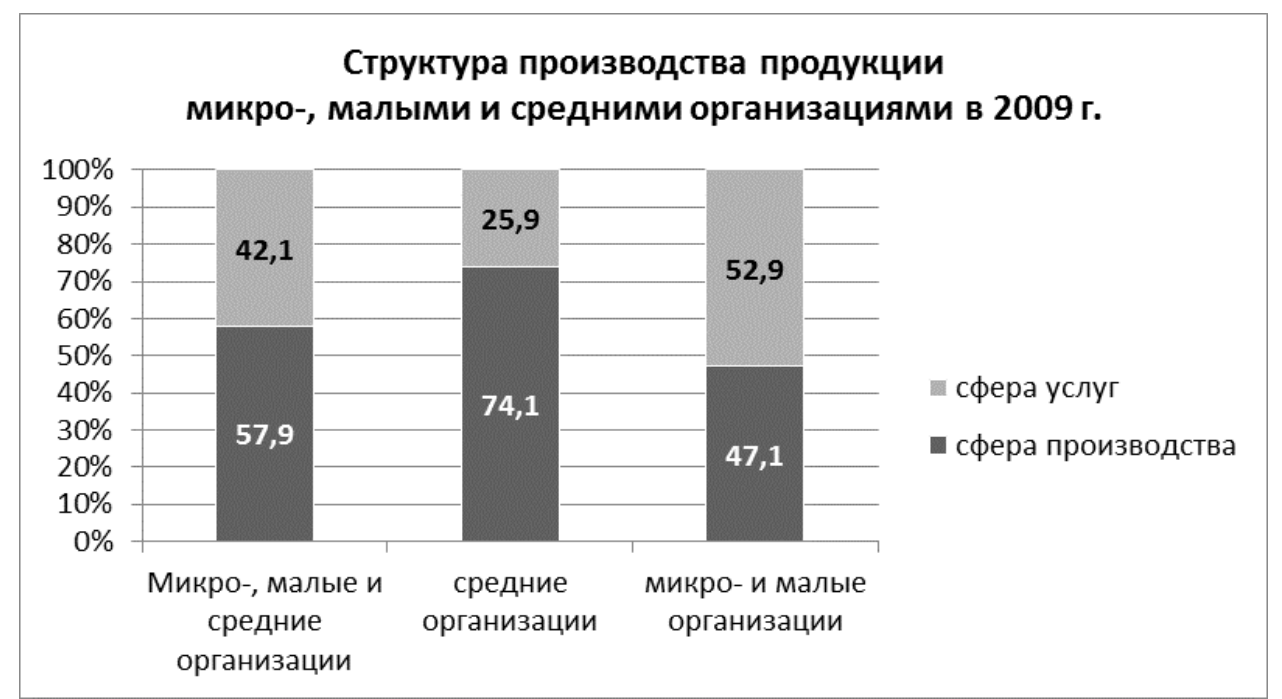

Рисунок 6. Структура производства продукции (работ, услуг) субъектами малого и среднего бизнеса по видам экономической деятельности в 2009 г. (расчеты автора по данным [1])

Проанализируем более детально структуру производимой продукции субъектами малого и среднего бизнеса по отраслям экономики.

Из производящих отраслей экономики в структуре производимой малым и средним бизнесом продукции лидирует обрабатывающая промышленность. Ее доля составила 55,8\% в 2013 г. (рис. 7). На долю строительства пришлось $26,2 \%$, на долю сельского хозяйства $-17,2 \%$.

Среди отраслей сферы услуг, в которой функционировал малый и средний бизнес в 2013 году, лидером является такой вид деятельности как торговля, ремонт автомобилей, бытовых изделий и предметов личного пользования (рис. $8)$. Его доля составила половину $(50,6 \%)$ всего объема производственной продукции малым и средним бизнесом в сфере услуг. Значительную долю в данном секторе занимают операции с недвижимостью $(22,0 \%)$, транспорт и связь (15,9\%). 


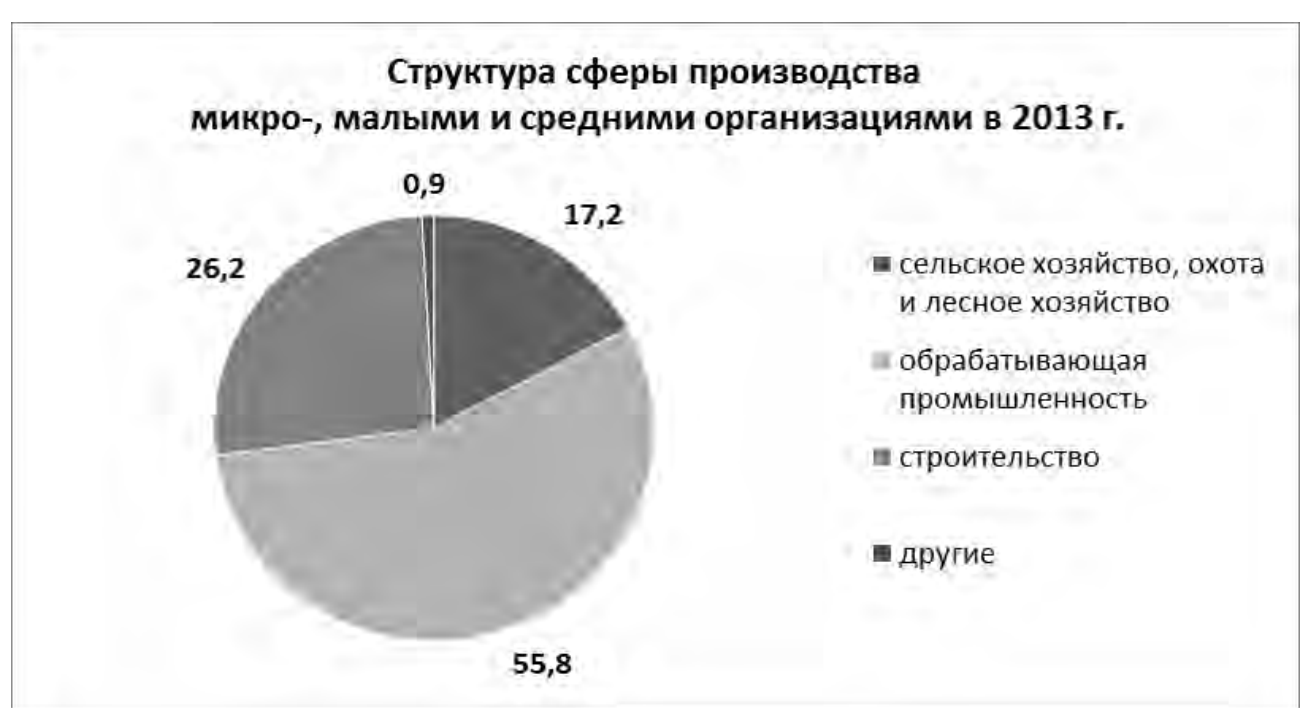

Рисунок 7. Структура производимой продукции субъектами малого и среднего бизнеса в отраслевом разрезе сферы производства (расчеты автора по данным [1])

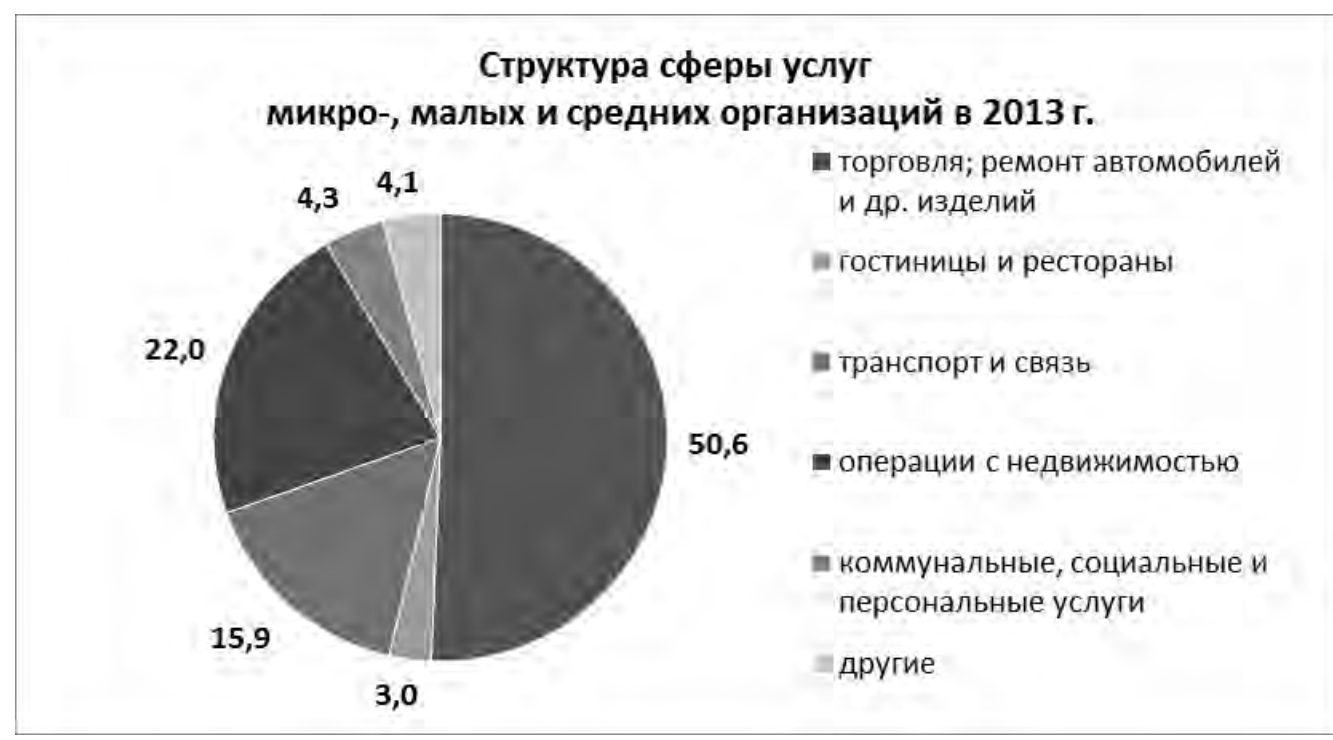

Рисунок 8. Структура производимой продукции субъектами малого и среднего бизнеса в отраслевом разрезе сферы услуг (расчеты автора по данным [1])

Для экономики Беларуси, имеющей многоотраслевую обрабатывающую промышленность, важно оценить вклад малых и средних предприятий в промышленное производство. Проанализируем производственную структуру субъектов малого и среднего бизнеса. В структуре производства продукции обрабатывающей промышленности (рис.9) малые и средние предприятия заняты преимущественно производством продукции машиностроения (20,6\% в 2013 г.), пищевой промышленности $(17,4 \%)$, металлургической промышленности $(13,1 \%)$, деревообрабатывающей и целлюлозно-бумажной промышленности $(10,7 \%)$, строительных материалов $(8,2 \%)$, химической и нефтехимической промышленности $(8,2 \%)$, легкой промышленности $(7,0 \%)$. Как видно на рис. 9 , структура производимой малыми и средними предприятиями продукции обрабатывающей промышленности за период с 2009 по 2013 годы изменилась незначительно. Наблюдается тенденция снижения доли пищевой промышленности и незначительного роста доли машиностроения, химической и нефтехимической промышленности, промышленности строительных материалов. Структурные сдвиги были лишь в 2011-2012 гг., которые связаны с резким ростом доли нефтепродуктов. Данная ситуация объясняется ростом экспорта растворителей и разбавителей за счет российского сырья в страны ЕС. Пик экспортных поставок пришелся на 2012 год, вследствие чего доля нефтепродуктов в структуре производства малым и средним бизнесом в данном году составила $17,8 \%$ против $0,6 \%$ в 2009 г. Однако из-за прекращения поставок сырья Российской Федерацией данный бизнес быстро прекратился, и производственная структура в 2013 году вернулась в прежние рамки (к уровню 2010 года). В 2013 г. доля производства нефтепродуктов составила 0,7\%. 


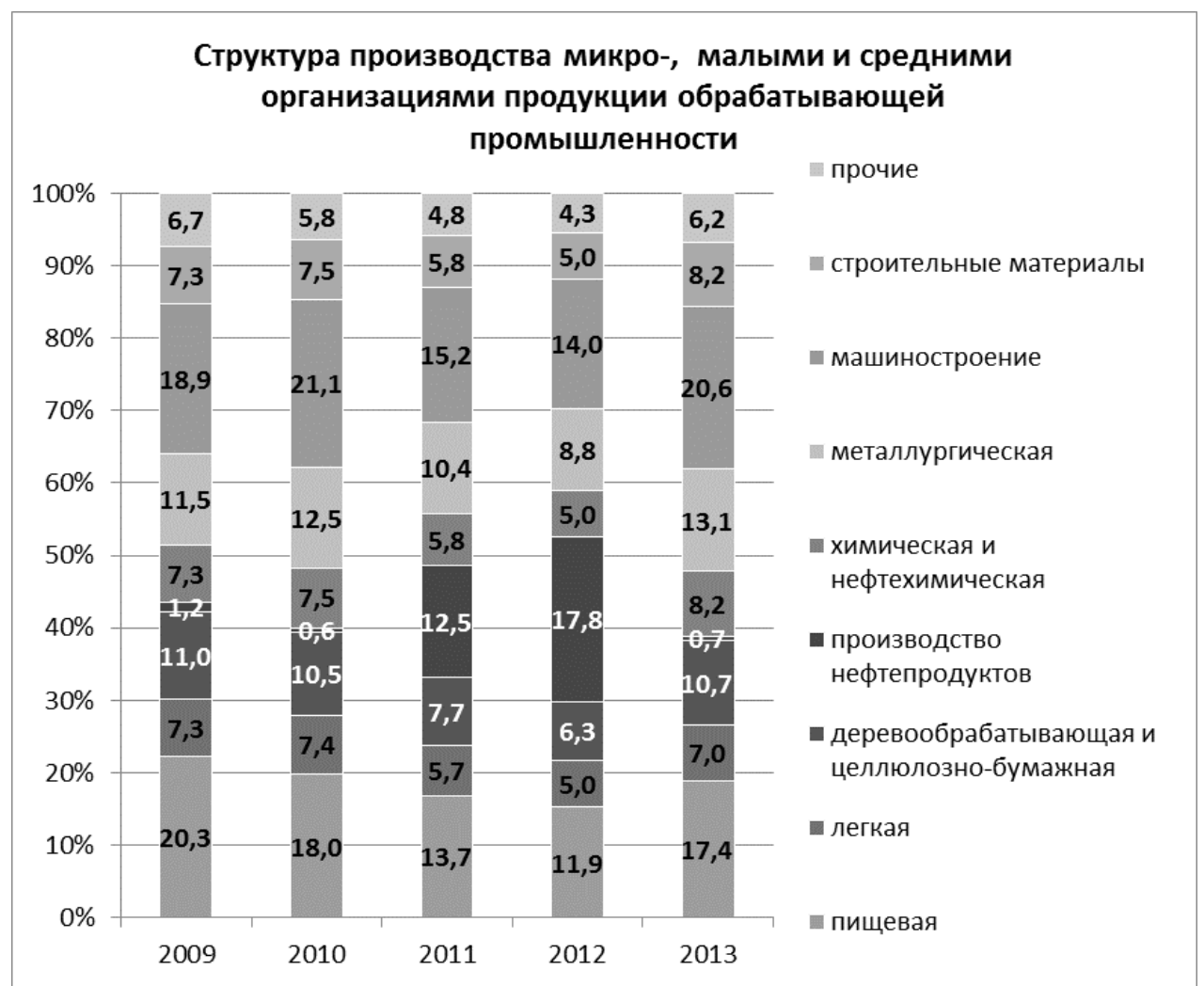

Рисунок 9. Структура обрабатывающей промышленности, произведенной субъектами малого и среднего бизнеса (расчеты автора по данным [1])

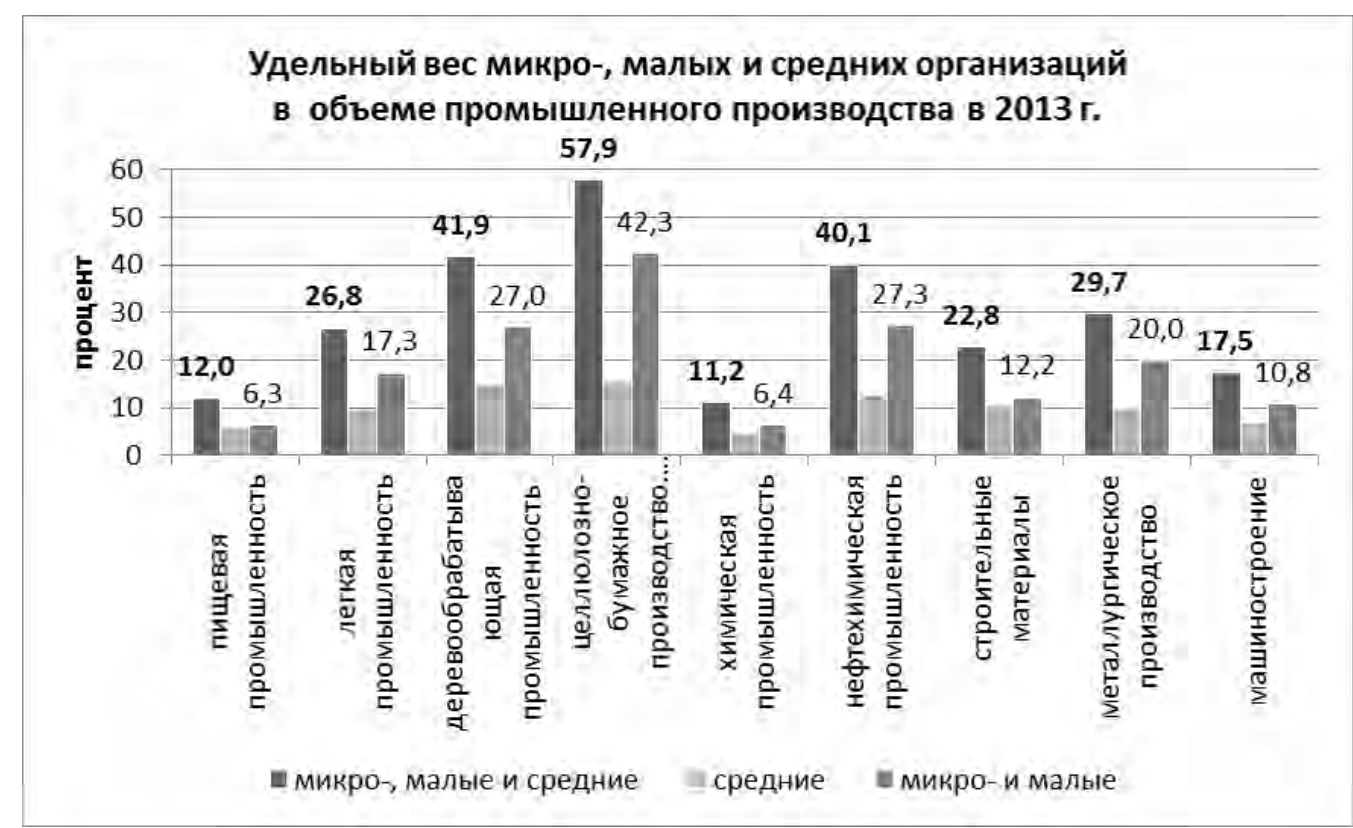

Рисунок 10. Удельный вес субъектов малого и среднего бизнеса в промышленном производстве в отраслевом разрезе в 2013 году (расчеты автора по данным [1], [2])

Оценивая вклад малого и среднего предпринимательства в производство отдельных отраслей обрабатывающей промышленности, можно отметить, что его доля в целлюлозно-бумажном производстве составила 57,9\% в 2013 г., в деревообрабатывающей промышленности - 41,9\%, нефтехимической промышленности - 40,1\%, металлургии - 29,7\%, легкой промышленности - 26,8\%, машиностроении - 17,5\%, пищевой промышленности - 12,0\% (рис. 10). Причем, во всех перечисленных отраслях более половины произведенной сектором малого и среднего бизнеса продукции, создано микро-организациями и малыми организациями.

Поступление иностранных инвестиций в реальный сектор экономики характеризует инвестиционный потенциал предприятий. Динамика поступающих в сектор малого и среднего бизнеса иностранных инвестиций положительная (рис. 11). По сравнению с 2009 годом, когда из всех поступающих в реальный сектор иностранных инвестиций малый и средний бизнес привлекал около четверти инвестиций, в 2013 году эта доля составила порядка 50\%. Наиболее привлекательными для иностранных инвестиций в секторе малого и среднего бизнеса являются малые организации. 


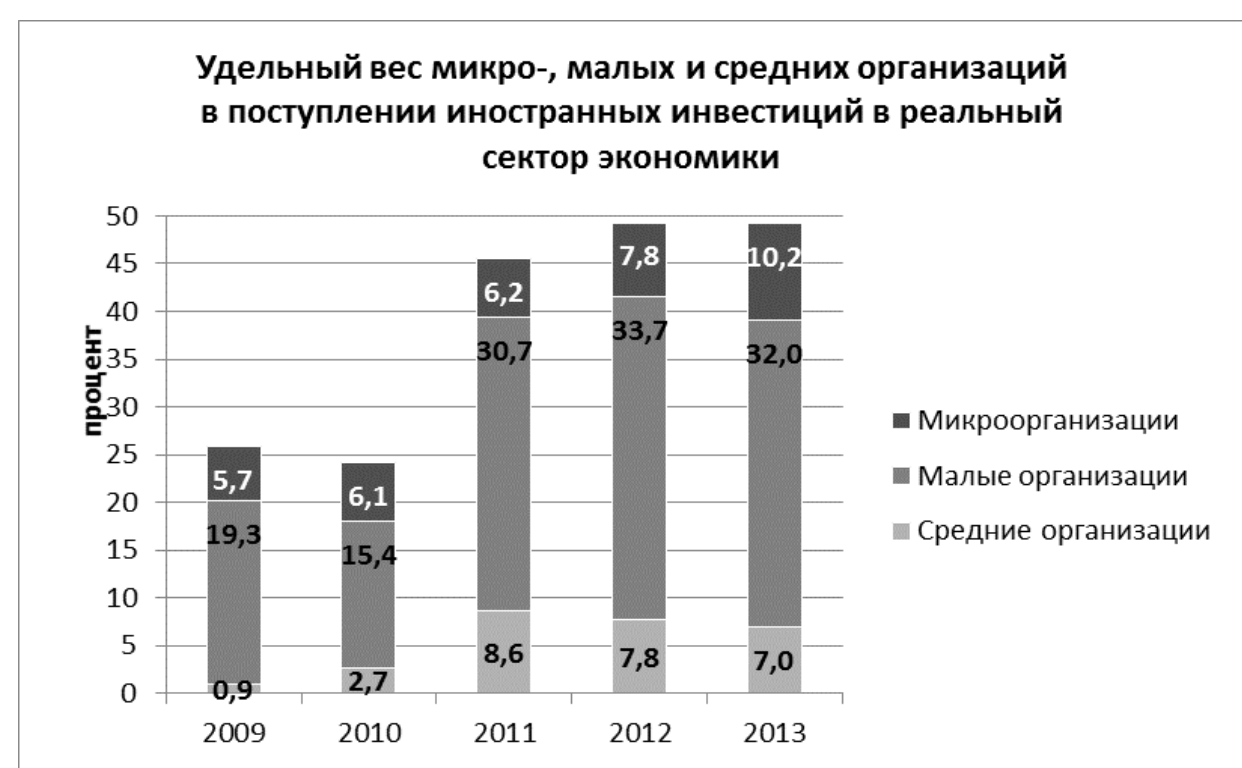

Рисунок 11. Доля субъектов малого и среднего бизнеса в поступлении иностранных инвестиций в реальный сектор экономики (расчеты автора по данным [1], [2])

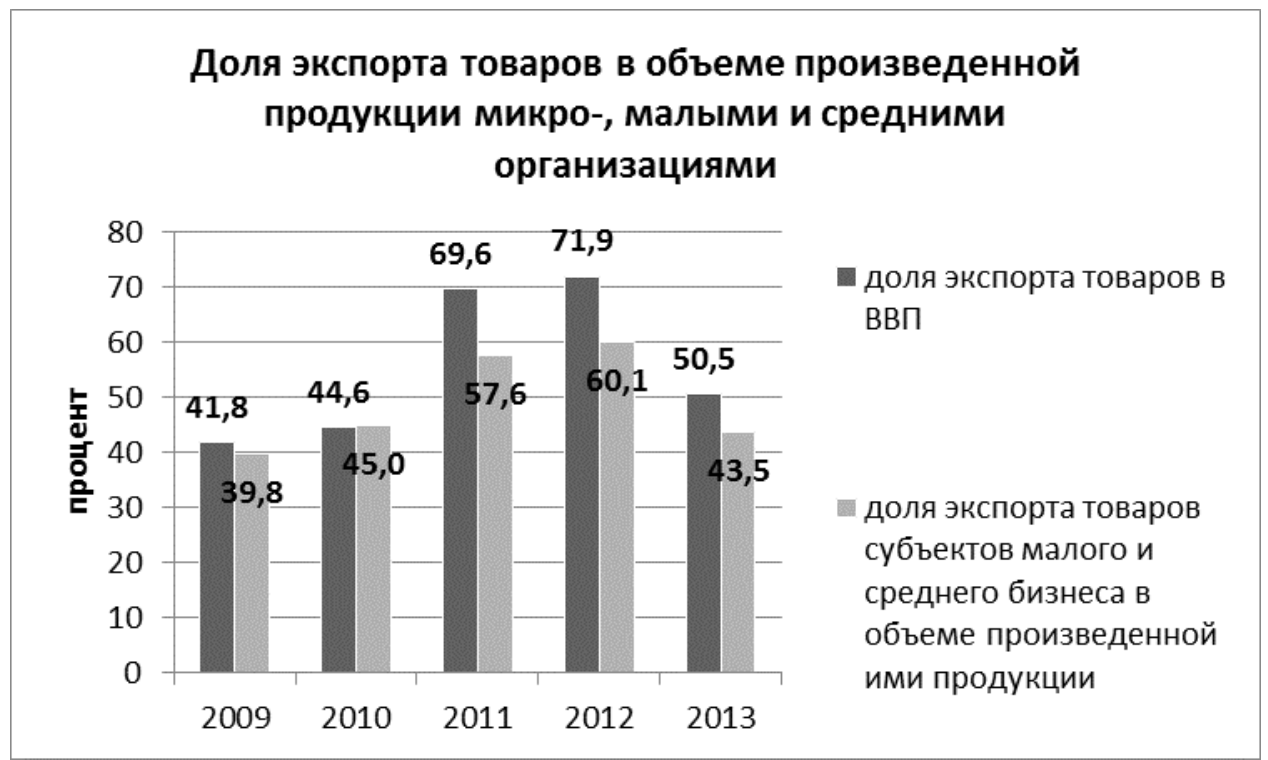

Рисунок 12. Включенность субъектов хозяйствования во внешнеэкономические связи (расчеты автора по данным [1], [2])

Доля экспорта в объеме произведенной продукции характеризует экспортный потенциал субъектов хозяйствования. Сравнивая долю товаров, идущую на экспорт, в общем объеме произведенной продукции малым и средним предпринимательством с республиканским уровнем, можно отметить значительный экспортный потенциал малого и среднего бизнеса (рис. 12). Доля его продукции, идущая на экспорт, составила 43,5\% в 2013 году. Резкий рост доли экспорта в 2011-2012 гг. объясняется эффектом девальвации, произошедшей в 2011 г. в Беларуси. Тезис о значительном экспортном потенциале у малого и среднего бизнеса подтверждается также тем, что его доля в экспорте Беларуси $(37,3 \%$ в 2013 г.) превышает долю в импорте $(35,7 \%)$ (рис. 1,2$)$, что способствует снижению отрицательного сальдо по текущему счету платежного баланса страны.

Изменение институциональных условий ведения бизнеса в Беларуси за рассматриваемый период можно оценить на основе рейтинга страны в международном исследовании «Doing Business» («Ведение бизнеса»), ежегодно проводимом Международной финансовой корпорацией, и опросов предпринимателей. В рейтинге Doing Business Беларусь поднялась с 85 места в 2009 году до 57 места в 2015 году. И, несмотря на то, что исследователи указывают на невысокую корреляцию между долей частного бизнеса в ВВП страны и ее позицией в рейтинге, улучшения по некоторым пунктам очевидны [3]. Наиболее значимый прогресс произошел по условиям регистрации предприятий (сокращение срока и затрат на регистрацию) и в области налогообложения (сокращены количество выплат, время уплаты, общая налоговая ставка, введена система электронного декларирования налогов). По-прежнему низкие позиции по условиям ведения международной торговли, условиям получения кредитов, процедурам неплатежеспособности и ликвидации предприятий.

Опросы предпринимателей, проводимые Исследовательским центром ИПМ о проблемах ведения бизнеса, показывают, что основными внешними барьерами для развития бизнеса в 2010 году [4] предприниматели называли недостаточную защиту имущественных прав и интересов частного бизнеса, неравные условия по сравнению с госсекто- 
ром, сложность налогового регулирования и высокие ставки налогов, бюрократические барьеры и ограничения, проверки и штрафы. Наряду с административными барьерами, мировой кризис усилил значимость экономических факторов: высокая конкуренция, высокие арендные ставки, дорогие кредитные ресурсы. Итоги опроса 2014 года [5] выявили следующие наиболее значимые внешние факторы, сдерживающие развитие бизнеса: арендные ставки, система проверок и штрафных санкций, бюрократические процедуры (регистрация, разрешения, лицензии и т.п.), уровень конкуренции на рынке, ставки на заемные средства, валютное регулирование. По-прежнему остаются высокими административные барьеры, к которым добавляются макроэкономические проблемы, связанные с падением покупательной способности населения, ростом неплатежей, ограничениями на валютном рынке.

Правительством осознается роль малого частного бизнеса как потенциального источника экономического роста, что продекларировано в принятых Директиве №4 «О развитии предпринимательской инициативы и стимулировании деловой активности в Республике Беларусь» от 31.12.2010, Декрете №6 «О стимулировании предпринимательской деятельности на территории средних, малых городских поселений, сельской местности» от 07.05.2012, Программе государственной поддержки малого и среднего предпринимательства на 2013-2015 года от 29.12.2012. В Национальной стратегии устойчивого социально-экономического развития Республики Беларусь на период до 2030 года, разработанной в 2015 г. (НСУР-2030), продекларированы такие цели в области развития малого и среднего бизнеса, как увеличение его доли в ВВП до 50\% к 2030 г., развитие партнерства и кооперации малого и среднего предпринимательства с крупным бизнесом, увеличение доли предпринимательства в региональном развитии.

\section{ВЫВОДЫ}

Оценка показателей функционирования малого и среднего предпринимательства в Беларуси за 2009-2014 гг. свидетельствует, что, несмотря на его невысокую долю в ВВП страны по сравнению с развитыми странами, имеется устойчивая тенденция роста его вклада в экономические показатели страны. При этом доля предприятий малого и среднего бизнеса в таких показателях как численность занятых, инвестиции в основной капитал, поступление иностранных инвестиций в реальный сектор экономики, экспорт товаров превышает его долю в ВВП, что свидетельствует о социальной роли малого и среднего предпринимательства, его инвестиционной активности и высоком экспортном потенциале. Вклад сектора малого бизнеса в экономические показатели является более значительным по сравнению со средним бизнесом. Положительные тенденции наблюдаются и в динамике отраслевой структуры производства. Сфера производства превалирует над сферой услуг. К основным видам услуг, предпочитаемым малым и средним бизнесом, относятся торговля, ремонт автомобилей, бытовых изделий и предметов личного пользования, транспорт и связь, операции с недвижимостью. В производственной сфере лидирует обрабатывающая промышленность, в структуре которой малые и средние предприятия предпочитают машиностроение, пищевую промышленность, металлургию, деревообрабатывающую и целлюлозно-бумажную промышленность (включая издательскую деятельность).

Таким образом, потенциал сектора малого и среднего предпринимательства в экономике Беларуси полностью не использован. Имеются проблемы в институциональной среде функционирования бизнеса: его чрезмерная зарегулированность, незащищенность в реализации прав собственности. Неблагоприятна и текущая макроэкономическая ситуация: нестабильность национальной валюты, дорогие кредитные ресурсы, снижение покупательского спроса на внутреннем и внешнем рынках. Учитывая значимость сектора малого предпринимательства для развития экономики, необходима детальная проработка мер экономической политики с учетом текущих тенденций и потребностей белорусской экономики.

\section{ЛИТЕРАТУРА}

1. Малое и среднее предпринимательство в Республике Беларусь: стат. сб. - Мн.: 2014.

2. Статистический ежегодник Республики Беларусь: стат. сб. - Мн.: 2014.

3. Официальный сайт группы Всемирного банка. Доклад «Ведение бизнеса». - Режим доступа: http://russian.doingbusiness.org/data/exploreeconomies/belarus. - Дата доступа: 28.06.2015.

4. Белорусский бизнес 2010: состояние, тенденции, перспективы / Исследовательский центр ИПМ, 2010. [Электронный ресурс]. - Режим доступа: http://www.research.by/analytics/businessbook/data/2010/ - Дата доступа: 10.06 .2015$.

5. Белорусский бизнес 2014: состояние, тенденции, перспективы / Исследовательский центр ИПМ, 2014. [Электронный ресурс]. - Режим доступа: http://www.research.by/analytics/businessbook/14/. - Дата доступа: 10.06.2015.

Статья поступила в редакцию 8 июля 2015 года. 